Celebes Abdimas: Jurnal Pengabdian Kepada Masyarakat

http://journal.lldikti9.id/CER/index

Vol 1, No, 2, Oktober 2019, pp 66-74

p-ISSN:2656-7938 dan e-ISSN: 2657-1870

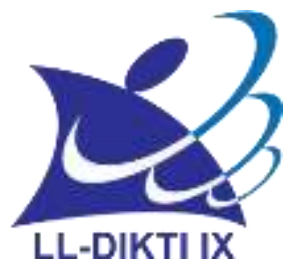

\title{
KKN-PPM Masyarakat Lingkar Pulau Wisata Camba-Cambang Kabupaten Pangkajene dan Kepulauan
}

\author{
Heriansah'1 , Fathuddin'2 ${ }^{2}$ Hartati Tamti², Yeni Savitri A. Lawi ${ }^{3}$, Arnold Kabangnga4, \\ Muhammad Ikramullah ${ }^{4}$ \\ ${ }^{1}$ Budidaya Perairan, Sekolah Tinggi Teknologi Kelautan(STITEK) Balik Diwa Makassar \\ Email: heriansah@stitek-balikdiwa.ac.id \\ 2 Ilmu Kelautan, Sekolah Tinggi Teknologi Kelautan(STITEK) Balik Diwa \\ 3 Teknologi Hasil Perikanan, Sekolah Tinggi Teknologi Kelautan(STITEK) Balik Diwa \\ ${ }^{4}$ Pemanfaatan Sumberdaya Perairan, Sekolah Tinggi Teknologi Kelautan(STITEK) Balik Diwa
}

\section{Artikel info}

\section{Artikel history:}

Received;September-2019

Revised: September-2019

Accepted;Oktober-2019

Publish: Oktober-2019
Keywords:

Fish apartment;

diversifikasi hasil

perikanan; sampah

plastik; sadar wisata;

IMTA
Abstrak. Tujuan pengabdian Kuliah Kerja Nyata - Pembelajaran dan Pemberdayaan Masyarakat (KKN-PPM) ini adalah memberdayakan masyarakat agar memiliki kapasitas sehingga dapat menjadi bagian dari pengelolaan pulau wisata Camba-cambang. dan meningkatkan kemampuan mahasiswa dalam melaksanakan pengabdian kepada masyarakat. Pendekatan pemberdayaan yang digunakan adalah participatory rural appraisal, participatory tecnology development, dan community development dengan metode pelatihan, demonstrasi plot, dan pendampingan. Program kerja yang dilaksanakan dinamakan Catur Program Kerja, yaitu : (1) Pengembangan fish apartment, (2) Diversifikasi olahan hasil perikanan dan desain kemasan, (3) Penanganan sampah plastik, dan (4) Budidaya sistem IMTA. Operasional kegiatan meliputi koordinasi dan sosialisasi, penyiapan administrasi, pelaksanaan panca program kerja, serta monitoring dan evaluasi. Evaluasi dilakukan dengan menggunakan instrumen pre test dan post test serta pengamatan dan penilaian kinerja. Program KKN-PPM di lingkar pulau wisata Camba-cambang dapat meningkatkan pengetahuan dan keterampilan kelompok sasaran yang terdiri dari nelayan dan pembudidaya, ibu-ibu rumah tangga dan remaja putri, organisasi pemuda, siswa sekolah dan anak-anak putus sekolah. Kelompok sasaran telah meningkat pengetahuan dan keterampilannya dalam memanfaatkan potensi sumberdaya pulau, khususnya yang terkait dengan catur program kerja. Program pengabdiaan KKN-PPM ini juga dapat meningkatkan kompetensi teknis mahasiswa dalam pemberdayaan masyarakat.

\section{Coresponden author:} Heriansah

Sekolah Tinggi Teknologi Kelautan(STITEK) Balik Diwa Makassar Jl. Lasuloro IV No. 2 Perumnas Antang Makassar Sulawesi Selatan Email: heriansah@stitek-balikdiwa.ac.id (c) (i) artikel dengan akses terbuka dibawah lisensi CC BY -4.0 
67| Celebes Abdimas: Jurnal Pengabdian Kepada Masyarakat

\section{PENDAHULUAN}

Pulau-pulau yang berada di Kabupaten Pangkajene Kepulauan (Pangkep) mempunyai potensi sumberdaya perikanan dan kelautan yang sangat besar, antara lain terumbu karang, potensi wisata serta beragam jenis ikan dan biota laut lainnya yang bernilai ekonomis (Heriansah dan Fathuddin, 2014). Salah satu pulau yang saat dikembangkan oleh Pemerintah Daerah Kabupaten Pangkep adalah Pulau Camba-cambang sebagai pulau wisata. Pulau wisata ini berada dalam wilayah administratif Desa Mattiro Baji Kecamatan Liukang Tupabbiring Utara. Desa Mattiro Baji terdiri dalam 4 pulau, yaitu Pulau Camba-cambang, Pulau Saugi, Pulau Satando, dan Pulau Sapuli (BPS Kabupaten Pangkep, 2018).

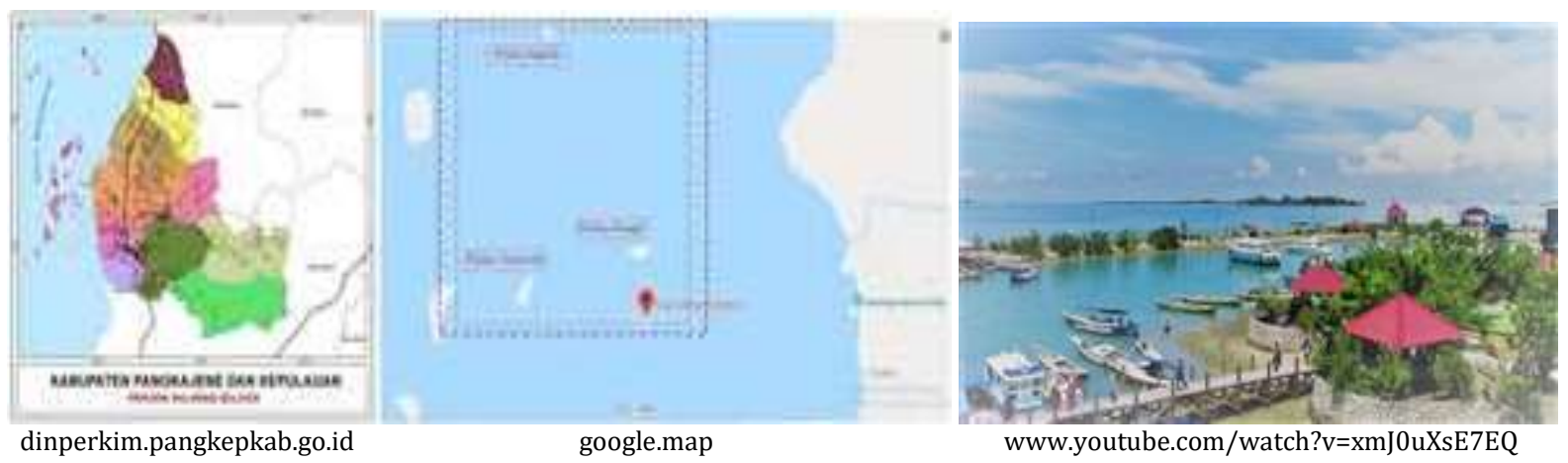

Gambar 1. Gambaran Pulau Wisata Cambang-cambang

Keterlibatan masyarakat merupakan unsur utama pada sistem pengembangan objek wisata. Keterlibatan sangat ditentukan oleh kapasitas masyarakat, baik sebagai objek maupun subjek pengelolaan wisata. Berdasarkan hasil observasi, bentuk-bentuk keterlibatan masyarakat sekitar pulau wisata Camba-cambang masih terbatas, hanya sebagai penjual makanan ringan, pekerja kebersihan, dan pengemudi kapal penyebrangan. Oleh karena itu, perlu dilakukan pemberdayaan masyarakat di lingkar pulau wisata Camba-cambang agar masyarakat memiliki kapasitas untuk menjadi bagian dari pengelolaan wisata. Masalah utama terkait dengan keterlibatan masyarakat di sekitar pulau wisata Camba-cambang dikelompokkan pada dua isu mendasar sebagai berikut : (1) Rendahnya pengetahuan dan keterampilan masyarakat dalam mengelola manfaat ekonomis dan peluang-peluang usaha yang ditimbulkan oleh keberadaan pulau wisata Camba-cambang. Umumnya masyarakat belum mampu menggerakkan dan menyelerasakan aktivitas aktivitas kesehariannya ke dalam ranah kepariwisataan, (2) Perilaku negatif masyarakat terkait dengan sanitasi dasar dan praktek pengelolaan perikanan yang tidak ramah lingkungan. Masyarakat masih terbiasa membuang sampah di laut dan menggunakan alat tangkap yang destruktif sehingga merusak lingkungan perairan. Jenis kerusakan lingkungan yang ditimbulkan antara lain patahan dan kematian karang akibat pemboman serta tumpukan sampah di pesisir pulau. Rusaknya kualitas lingkungan tersebut yang berada disekitar pulau wisata Camba-cambang akan mempengaruhi kualitas pulau wisata tersebut..

Solusi untuk mengatasi masalah tersebut di atas adalah penerapan iptek dalam meningkatkan kapasitas masyarakat dalam mengelola potensi perikanan di lingkar pulau wisata Camba-cambang. Solusi dioperasionalkan dalam bentuk program kerja yang disebut Catur Program Kerja, yaitu : (1) Pengembangan fish apartment, (2) Diversifikasi olahan hasil perikanan dan desain kemasan, (3) Penanganan sampah laut, dan (4) Budidaya rumput laut metode vertikal sistem IMTA. Kelima program kerja ini berorientasi dalam mendukung pengembangan pulau wisata Camba-cambang.

Terumbu karang di perairan sekitar pulau wisata Camba-cambang sebagai habitat penting ikan sudah mulai rusak akibat cara penangkapan nelayan yang tidak ramah lingkungan. Salah satu teknik yang telah banyak dikembangkan untuk memperbaiki terumbu karang alami yang rusak adalah terumbu karang buatan. Fish apartment merupakan terumbu buatan yang ditempatkan di dasar perairan yang berfungsi sebagai tempat memijah bagi ikan-ikan dewasa dan atau areal perlindungan, asuhan dan pembesaran bagi telur, larva serta anak-anak ikan, 
KKN PPM Masyarakat Lingkar Pulai (Hariansyah, Fatahuddin, Tamti, Safitri, Lawi, Kabangnga, Ikramullah) | 68

memulihkan ketersediaan (stok) sumberdaya ikan, sebagai rumpon untuk menciptakan daerah penangkapan buatan, dan berpotensi meningkatkan nilai ekonomi pesisir (Budhiman, 2011; Bambang et al., 2011; Rendle dan Rodwell, 2014). Oleh karena itu, fish apartment memiliki fungsi ekologis dan ekonomis yang penting serta berpotensi sebagai spot wisata bawah laut. Fish apartment diharapkan dapat memperkaya jenis ikan dan memperbaiki lingkungan perairan sehingga berkontribusi dalam pengembangan pulau wisata Camba-Cambang.

Masyarakat disekitar pulau wisata Camba-cambang umumnya menjual produk perikanan dalam bentuk segar yang daya simpannya singkat. Upaya untuk memperpanjang masa simpan ikan dapat dilakukan melalui diversifikasi, yaitu penganekaragaman jenis produk olahan hasil perikanan dari bahan baku yang belum atau sudah dimanfaatkan dengan tetap memperhatikan mutu dan gizi untuk mendapatkan nilai tambah produk (Rahadi et al., 2001). Diversifikasi diharapkan mampu menjadi penggerak perekonomian masyarakat yang berbasis pada usaha yang selama ini telah dijalankan, namun belum mendapat perhatian secara serius (Karim et al., 2013). Untuk lebih meningkatkan nilai tambak diversifikasi olahan, perlu dilakukan pengemasan sebagai pelindung isi, pemberi daya tarik, identitas produk, dan memudahkan proses distribusi (Tjiptono, 1999). Diversifikasi dan desain kemasan olahan hasil perikanan diharapkan menjadi alternatif usaha masyarakat serta dapat menjadi oleh-oleh khas pulau wisata Camba-cambang.

Sampah laut menjadi isu penting saat ini karena lebih dari 250.000 ton sampah plastik telah terapung di lautan (Eriksen et al, 2014), lebih dari 4 juta ton teridentifikasi berada di lautan (Haward, 2018). Indonesia adalah negara terbesar ke-2 di dunia yang diperkirakan menyumbang jumlah sampah yang masuk ke lautan (Jambeck et al., 2015). Sumber sampah laut lain wisata pantai, aktivitas nelayan, sampah permukiman, dan industri yang berdampak secara ekologis, ekonomis, dan kesehatan (NOAA, 2013). Ancaman sampah di lingkungan laut menjadi penting karena memiliki resiko dampak terhadap manusia (Farrell dan Nelson, 2013) yang disebabkan ada interaksi antara laut dan manusia (Fleming at al., 2014) maupun melalui mekanisme transfer dari sumber makanan, seperti ikan dan moluska (Willoughby, 1997). Selain itu, sampah laut seperti plastik mempengaruhi jumlah biota (Uneputty dan Evans, 1997) dan diduga agen terhadap penyakit terumbu karang (Harrison et al., 2011). Mengacu pada berbagai dampak negatif yang dihasilkan, maka perlu penanganan sampah laut, termasuk di perairan laut Desa Mattiro Baji. Perairan laut di wilayah ini merupakan perairan yang paling dekat dengan wilayah daratan Kabupaten Pangkep dan merupakan bagian dari Pulau Wisata Camba-Cambang serta wilayah perairan yang terdiri dari beberapa pulau dengan berbagai aktivitas penduduk. Ketiga faktor ini merupakan potensi dan titik awal sumber masuknya sampah ke laut.

Perairan Desa Mattiro Baji merupakan wilayah yang paling dekat dengan wilayah daratan Kabupaten Pangkep dan merupakan bagian dari Pulau Wisata Camba-Cambang yang rentan terhadap buangan limbah. Limbah yang terbuang diperairan pada prinsipnya mengandungn nutrien yang dapat dimanfaatkan untuk kegiatan budidaya melalui pengaturan aliran nutrien. IMTA merupakan sistem akuakultur dengan konsep utama mendaur ulang limbah menjadi sumber makanan bagi organisme yang berbeda level trofiknya melalui pengintegrasian komponen organisme secara sinergis (Buck et al., 2018). IMTA memiliki konsep penggabungan beberapa spesies organisme dari tropik level berbeda, yaitu spesies yang diberi pakan (ikan/udang) dan spesies ekstraktif partikel organik (misalnya kerang, teripang, landak laut, ikan herbivora) serta spesies ekstraktif anorganik terlarut, misalnya rumput laut (Jena dan Saha, 2017; Zhang, et al., 2015). Konsep IMTA sangat variatif sehingga dapat diterapkan di air laut, payau, dan tawar serta perairan darat dan laut dengan prinsip bahwa organisme yang dipilih berada pada berbagai tingkatan trofik (Chopin e al., 2012). Budidaya sistem IMTA memiliki dampak ekologis, ekonomis, dan sosial yang diharapkan berkontribusi dalam peningkatan pendapatan masyarakat dan pengembangan pulau wisata Camba-cambang.

Tujuan pengabdian KKN-PPM ini adalah memberdayakan masyarakat sehingga memiliki kapasitas untuk berperan dalam pengelolaan pulau wisata Camba-cambang serta menjadi media pembelajaran bagi mahasiswa. Program KKN-PPM ini diharapkan dapat bermanfaat dalam meningkatkan kinerja pengelolaan sumberdaya secara optimal dan meningkatkan kesadaran masyarakat dalam mengelola sumberdaya perikanan secara berkelanjutan. KKN-PPM ini juga diharapkan dapat meningkatkan kompetensi mahasiswa terkait dengan ilmu yang ditekuninya. 
69| Celebes Abdimas: Jurnal Pengabdian Kepada Masyarakat

\section{METODE}

Program KKN-PPM ini dilaksanakan pada tanggal 02 Juli sampai dengan 07 Agustus 2019 di 3 pulau yang berada di lingkar pulau wisata Camba-cambang. Langkah-langkah pelaksanaan KKN-PPM sebagai berikut :

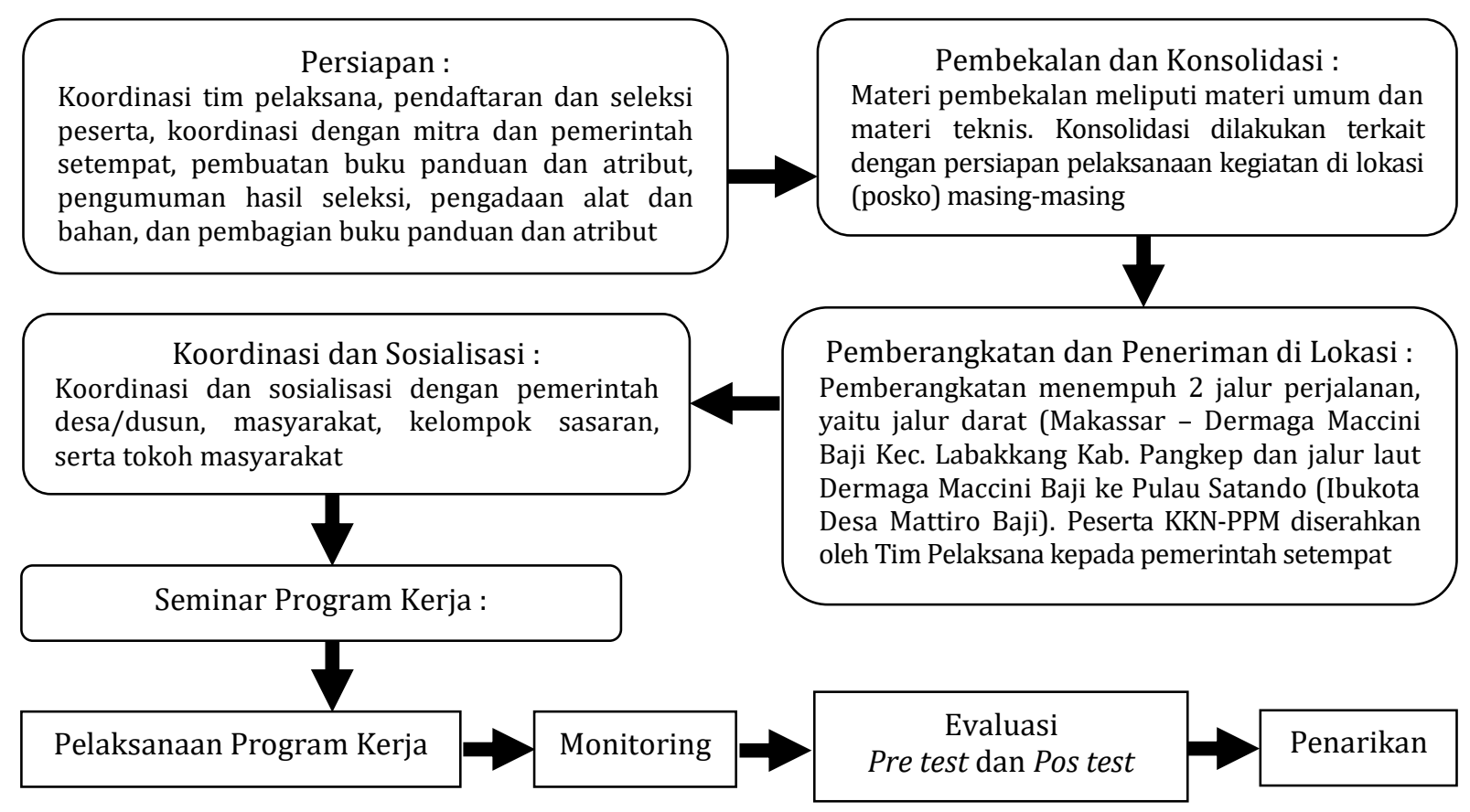

Gambar 2. Langkah-langkah Pelaksanaan KKN-PPM
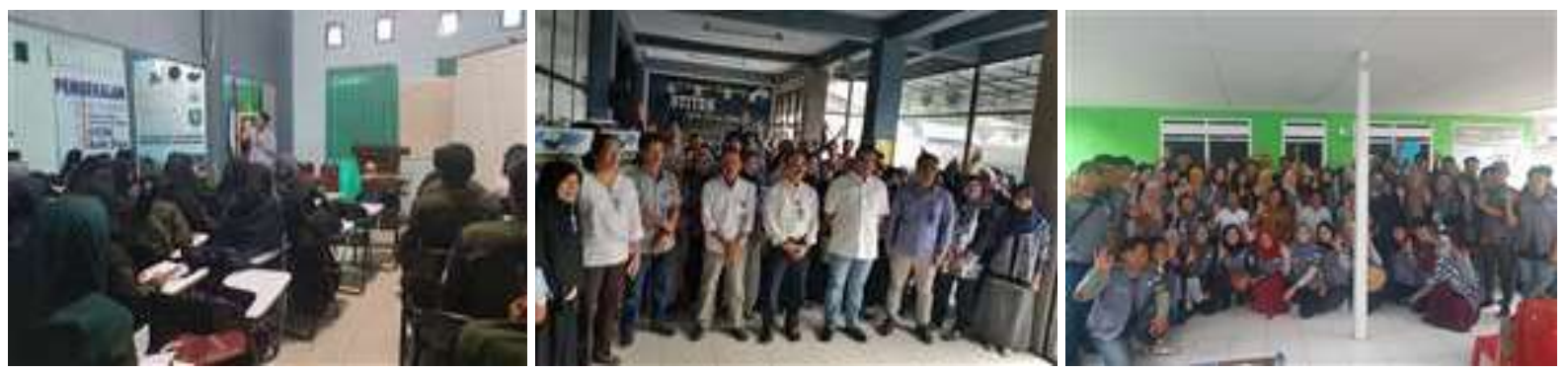

Gambar 3. Dokumentasi Pembekalan, Pelepasan, dan Penerimaan KKN-PPM

a. Program pengabdian ini diimplementasikan dengan menggunakan pendekatan: (1) Participatory Rural Appraisal yang menekankan keterlibatan mitra/kelompok sasaran dalam keseluruhan kegiatan mulai dari perencanaan, pelaksanaan, dan evaluasi program, (2) Participatory Tecnology Development yang memanfaatkan teknologi tepat guna yang berbasis pada hasil riset dan kearifan lokal, dan (3) Community Development yaitu pendekatan yang melibatkan mitra/kelompok sasaran secara langsung sebagai subyek dan obyek pelaksanaan program. Metode pemberdayaan yang digunakan antara lain : (a) Pelatihan, yaitu pemberdayaan yang dilakukan melalui kegiatan pelatihan, baik pelatihan non-teknis maupun teknis kepada mitra/kelompok sasaran untuk memberikan tambahan pengetahuan tentang kepariwisataan dan peran masyarakat serta tambahan keterampilan tentang teknis pelaksanaan masing-masing program kerja. Pada metode ini kelompok sasaran diberikan buku panduan pelaksanaan program, (b) Demonstrasi plot (demplot), yaitu pemberdayaan yang dilakukan melalui praktek/ demonstrasi langsung yang dilakukan secara bersama-sama antara tim pelaksana dan mahasiswa dengan kelompok sasaran, dan (c) Pendampingan, yaitu pemberdayaan yang dilakukan dengan mendampingi dan memfasilitasi kelompok sasaran dalam melaksanakan program kerja. 


\section{HASIL DAN PEMBAHASAN}

\section{Pengembangan Fish Apartement}

Program kerja pengembangan fish apartment dilaksanakan dengan langkah-langkah: persiapan alat dan bahan, pembuatan konstruksi, dan penurunan konstruksi. Fish apartment dikonstruksi dari material balok dari kayu yang sifatnya organik dan ramah lingkungan. Wadah dikonstruksi berbentuk prisma dengan ketinggian $100 \mathrm{~cm}$, ukuran pada dasar prisma $80 \times 80 \mathrm{~cm}$ dan ukuran puncak prisma $20 \times 20 \mathrm{~cm}$. Fish apartment dipasang dengan model 4 koloni pada kedalaman $7 \mathrm{~m}$. Konstruksi dirangkai menjadi satu dengan menggunakan pemberat dari cor semen serta tali jangkar sebagai penghubung agar wadah tidak bergeser.
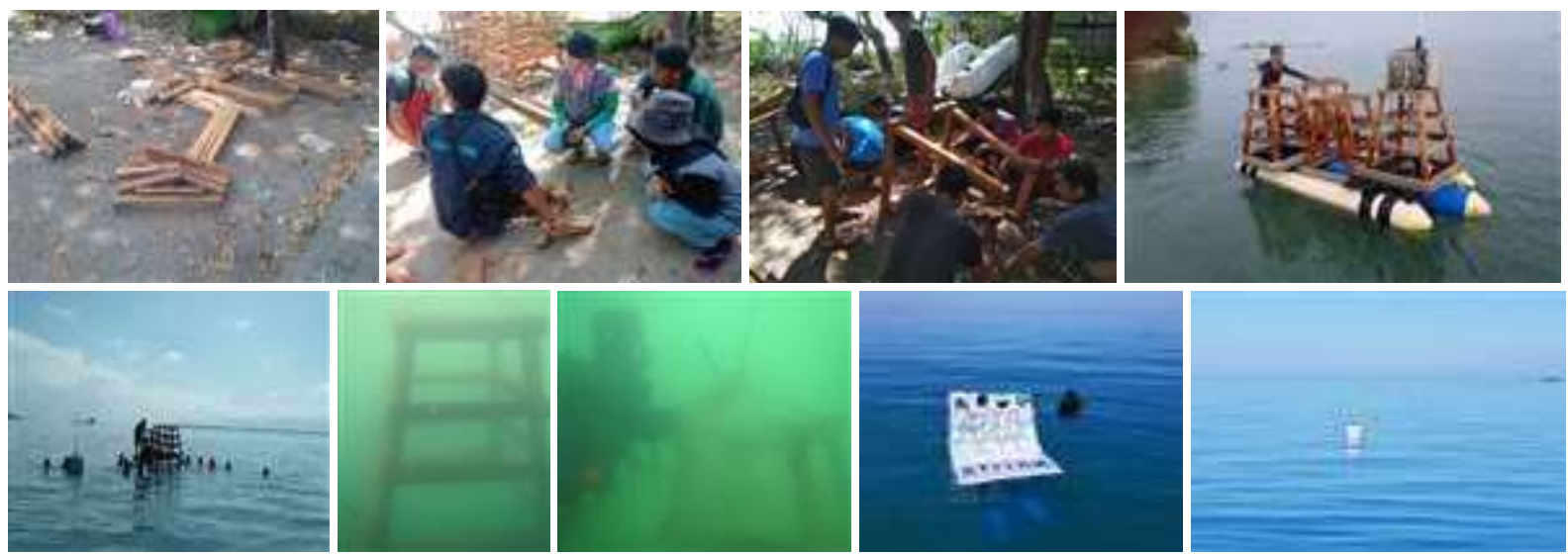

Gambar 4. Pelaksanaan Program Kerja Pengembangan Fish Apartment

Program kerja fish apartment diimplementasikan dengan pendekatan pembelajaran dan pemberdayaan yang menekankan keterlibatan mahasiswa dan mitra/kelompok sasaran secara aktif dan langsung pada keseluruhan kegiatan. Keterlibatan masyarakat pada pelaksanaan program kerja ini sangat tinggi yang ditandai dengan partisipasi dalam mempersiapkan alat dan bahan serta membuat dan menurunkan konstruksi. Hasil pelaksanaan program kerja ini menunjukkan peningkatan pengetahuan dan keterampilan kelompok sasaran terkait dengan pentingnya fish apartment terhadap aktivitas kepariwisataan. Hasil pre test menunjukkan bahwa dari 20 kelompok sasaran yang nilai, hanya 20\% yang memahami konsep dan teknis pengembangan fish apartment. Setelah dilakukan pelatihan, demplot, dan pendampingan, hasil post test menunjukkan tingkat pemahaman meningkat menjadi $85 \%$. Peningkatan pengetahuan dan keterampilan kelompok sasaran serta keberadaan fish apartment sekitar pulau wisata Camba-cambang dapat menjadi modal awal dalam pengembangan fish apartment untuk mendukung pengembangan wisata, termasuk menjadi alternatif spot wisata selam. Disamping itu dapat berfungsi secara ekologis bagi lingkungan perairan dan secara ekonomis bagi masyarakat setempat (Budhiman, 2011; Bambang et al., 2011; Rendle dan Rodwell, 2014).

\section{Diversifikasi Olahan Hasil Perikanan}

Jenis olahan dari pelaksanaan program kerja diversifikasi olahan hasil perikanan adalah nuget gonad landak laut jenis Deadema setosum yang ketersediannya sangat banyak di perairan sekitar pulau wisata Camba-cambang. Tahapan pembuatan nugget landak laut sebagai berikut :

a. Gonad dan telur diambil dengan membedah cangkang dan membersihkannya dengan menggunakan air tawar dan disimpan dalam satu wadah yang bersih.

b. Pembuatan bumbu yang terdiri dari merica, garam, tepung terigu, telur ayam, susu UHT full cream, keju, air es secukupnya, bawang putih dan bawang merah. Bahan pengikat tepung maizena, tepung roti dan air matang secukupnya.

c. Gonad dan telur yang telah bersih selanjutnya dicampurkankan ke dalam bahan bumbu sehingga menjadi adonan nugget untuk selanjutnya dilakukan pengukusan.

d. Setelah matang, nugget diangkat dari panci pengukusan kemudian didiamkan selama 45-60 menit dan selanjutnya dicetak sesuai dengan keinginan. 
71| Celebes Abdimas: Jurnal Pengabdian Kepada Masyarakat

e. Setelah dicetak, masukkan nugget kedalam wadah yang sudah berisi tepung maizena (sebelumnya campurkan dulu tepung maizena dengan air matang sampai agak mengental) angkat kemudian lumuri dengan tepung roti.

f. Setelah terbalur dengan tepung roti dilanjutkan dengan proses penggorengan. Setelah matang yang ditandai dengan warna kuning keemasan, angkat dan dinginkan untuk selanjutnya dilakukan proses pengemasan.

g. Pengemasan dibuat dengan label yang memuat logo STITEK Balik Diwa dan logo Kemenristekdikti, KKN-PPM 2019, dan merk produk. Wadah kemasan menggunakan bahan kraft dan bagian dalam menggunakan bahan aluminium foil, sedangkan label kemasan dibuat dari kertas stiker.

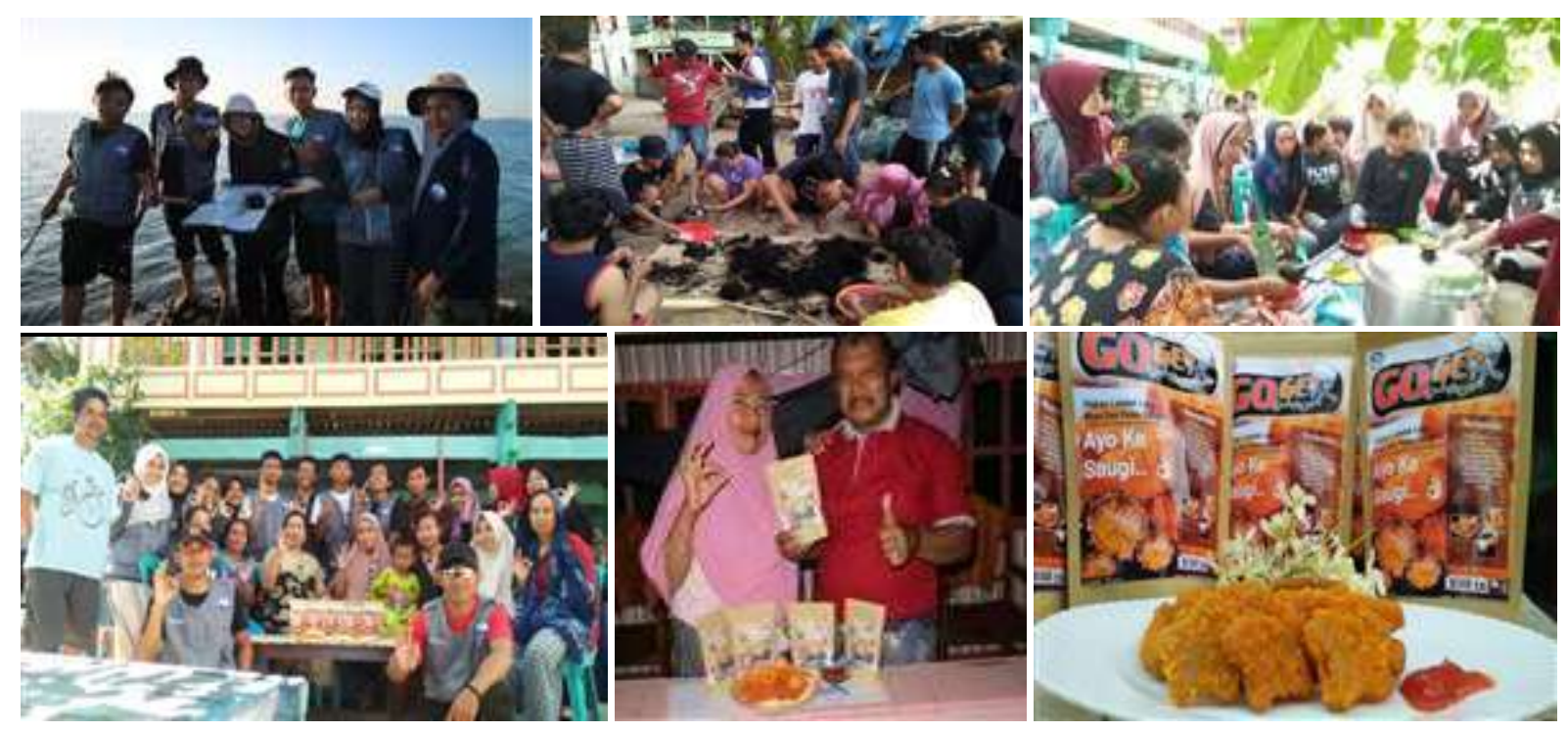

Gambar 5. Pelaksanaan Program Kerja Diversifikasi dan Pengemasan Olahan Hasil Perikanan

Program kerja diversifikasi olahan nuget gonad landak laut diimplementasikan dengan pendekatan pembelajaran dan pemberdayaan yang menekankan keterlibatan mahasiswa dan mitra/kelompok sasaran secara aktif dan langsung pada keseluruhan kegiatan. Keterlibatan masyarakat pada pelaksanaan program kerja ini sangat tinggi yang ditandai dengan partisipasi dalam mempersiapkan alat dan bahan serta membuat produk dan kemasan. Hasil pelaksanaan program kerja ini menunjukkan peningkatan pengetahuan dan keterampilan kelompok sasaran terkait dengan pentingnya fish apartment terhadap aktivitas kepariwisataan. Hasil pre test menunjukkan bahwa dari 20 kelompok sasaran yang nilai, belum ada $(0 \%)$ yang mengetahui cara pembuatan nuget gonad landak laut. Setelah dilakukan pelatihan dan pendampingan sebanyak 2 kali, hasil post test menunjukkan tingkat pemahaman meningkat menjadi $75 \%$. Peningkatan pengetahuan dan keterampilan kelompok sasaran dalam membuat nuget landak laut dapat dijadikan sebagai alternatif usaha yang dapat meningkatkan pendapatan masyarakat serta dapat menjadi oleh-oleh kuliner khas pulau wisata Camba-cambang. Kuliner dewasa ini menjadi salah satu daya tarik wisatawan untuk mengunjungi suatu daerah (Kristiana et al., 2018). Pengembangan pariwisata yang berbasis sumber daya lokal akan memberikan efek ganda terhadap sektor ekonomi lainnya melalui peningkatan nilai tambah dan kenaikan pendapatan masyarakat (Besra, 2012).

\section{Penanganan Sampah Laut}

Penanganan sampah laut dilakukan melalui metode 3R dengan membuat paving blok dari sampah plastik. Prosedur pembuatan paving blok berbahan sampah plastik sebagai berikut :

a. Pembuatan cetakan paving dari kayu dengan model segiempat dan ukuran yang disesuaikan dengan keinginan.

b. Pelelehan plastik dilakukan dengan menggunakan drum yang diisi oli bekas kemudian dipanaskan sampah mendidih.

c. Selanjutnya plastik dimasukkan sehingga meleleh menyerupai bubur yang kental. 


\section{KKN PPM Masyarakat Lingkar Pulai (Hariansyah, Fatahuddin, Tamti, Safitri, Lawi, Kabangnga, Ikramullah) | 72}

d. Plastik yang telah meleleh selanjutnya dicampur dengan pasir dan/atau kerikil dengan komposisi $60: 40$ pada suhu $100-150^{\circ} \mathrm{C}$ dan diaduk secara kontinyu sehingga diperoleh adukan kental yang rata.

e. Adukan dituangkan ke dalam cetakan yang telah dilumuri dengan minyak untuk mencegah lengket. Adukan dipres sehingga menjadi kompak dan dibiarkan hingga mengeras dan selanjutnya dilepaskan dari cetakannya.

f. Pengeringan dilakukan di bawah sinar matahari selama 24 jam.

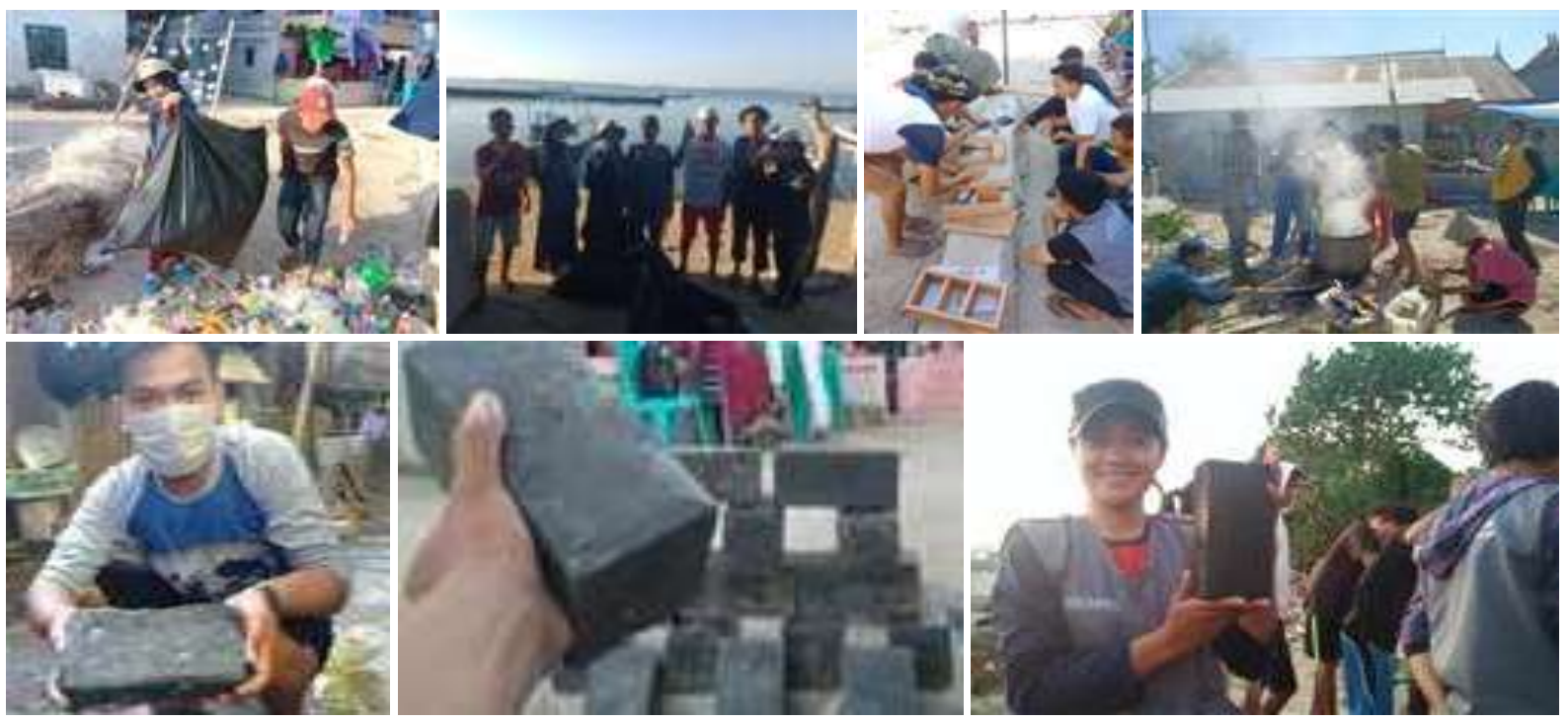

Gambar 6. Pelaksanaan Program Kerja Pembuatan Paving Blok dari Sampah Laut Plastik

Program kerja penanganan sampah laut plastik melalui pembuatan pavong blok diimplementasikan dengan pendekatan pembelajaran dan pemberdayaan yang menekankan keterlibatan mahasiswa dan mitra/kelompok sasaran secara aktif dan langsung pada keseluruhan kegiatan. Keterlibatan masyarakat pada pelaksanaan program kerja ini sangat tinggi yang ditandai dengan partisipasi dalam mempersiapkan alat dan bahan serta membuat paving blok. Hasil pelaksanaan program kerja ini menunjukkan peningkatan pengetahuan dan keterampilan kelompok sasaran terkait dengan pentingnya fish apartment terhadap aktivitas kepariwisataan. Hasil pre test menunjukkan bahwa dari 20 kelompok sasaran yang nilai, belum ada $(0 \%)$ yang mengetahui cara pembuatan paving blok dari sampah plastik. Setelah dilakukan pelatihan dan pendampingan sebanyak 3 kali, hasil post test menunjukkan tingkat pengetahuan dan keterampilan meningkat menjadi 85\%. Peningkatan pengetahuan dan keterampilan kelompok sasaran dalam membuat paving blok dari sampah platik dapat dijadikan sebagai alternatif cara mengurangi tumpukan sampah plastik di pesisir dan laut. Hal ini dapat berdampak terhadap kebersihan lingkungan yang berpengaruh pengembangan pulau wisata Camba-cambang. Sampah menjadi ancaman bagi sektor pariwisata (Sutrisnawati dan Puwarhita, 2018). Partisipasi masyarakat dalam pengelolaan sampah selain dapat mengurangi beban lingkungan, juga dapat menciptakan nilai ekonomis bagi masyarakat apabila sampah dapat dirubah menjadi sesuatu yang berguna dan bermanfaat (Mujiburrahmad dan Firmansyah, 2014)

\section{Budidaya Sistem IMTA}

Program kerja budidaya sistem IMTA menggunakan biota rumput laut, kerang hijau, landak laut, dan ikan baronang. Ikan yang digunakan berbobot $20,0 \pm 0,5 \mathrm{~g} /$ ekor, kerang hijau $5,0 \pm 0,5 \mathrm{~g} /$ ekor, landak laut 10,0 $\pm 0,5 \mathrm{~g} /$ ekor, dan rumput laut 15,0 $\pm 0,5 \mathrm{~g} / \mathrm{ikat}$. Keempat biota ini diambil dari perairan di sekitar lokasi KKN-PPM. Pemeliharaan diawali dengan memasukkan biota ke dalam wadah dengan terlebih dahulu dilakukan penimbangan bobot sebagai bobot awal pemeliharaan. Ikan dan landak laut dipelihara dengan kepadatan masing-masing 15 ekor/ wadah, kerang hijau 20 ekor/wadah (5 ekor per basket). Bobot total rumput laut yang dibutuhkan sekitar $3 \mathrm{~kg}$. Selama pemeliharaan, ikan diberikan pakan berupa pellet dan/atau ikan rucah setiap hari $\left(08 . .^{00}\right.$ dan $\left.16 .{ }^{\circ 0}\right)$ sebanyak $10 \%$ dari biomassa 

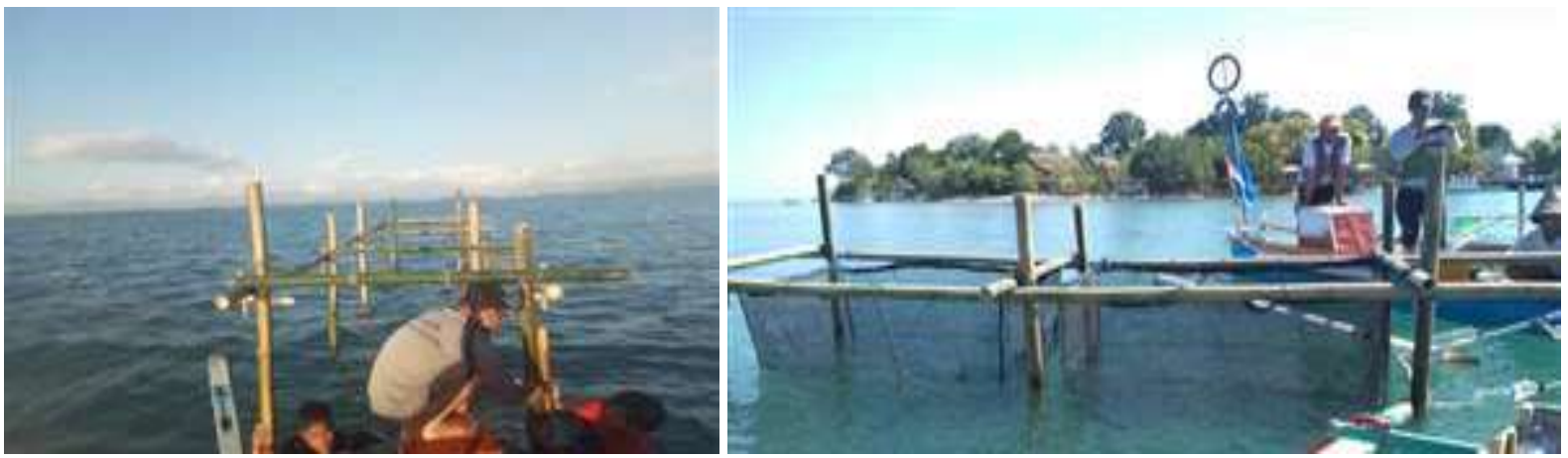

Gambar 7. Pelaksanaan Program Kerja Budidaya Sistem IMTA

Program budidaya sistem IMTA diimplementasikan dengan pendekatan pembelajaran dan pemberdayaan yang menekankan keterlibatan mahasiswa dan mitra/kelompok sasaran secara aktif dan langsung pada keseluruhan kegiatan. Keterlibatan masyarakat pada pelaksanaan program kerja ini sangat tinggi yang ditandai dengan partisipasi dalam mempersiapkan alat dan bahan serta membuat konstruksi. Hasil pelaksanaan program kerja menunjukkan peningkatan pengetahuan dan keterampilan terkait dengan budidaya sistem IMTA terhadap aktivitas kepariwisataan. Hasil pre test menunjukkan bahwa 50\% dari 20 kelompok sasaran yang nilai telah yang mengetahui budidaya sistem IMTA. Setelah dilakukan pelatihan dan pendampingan sebanyak 2 kali, hasil post test menunjukkan tingkat pengetahuan dan keterampilan meningkat menjadi 85\%. Peningkatan pengetahuan dan keterampilan kelompok sasaran dalam budidaya sistem IMTA dapat dijadikan sebagai alternatif usaha untuk peningkatan pendapatan dan pengembangan wisata. Aplikasi sistem IMTA berdampak positif terhadap aspek pemanfaatan nutrien dari beberapa biota budidaya, aspek produktivitas komoditas yang dibudidayakan, dan aspek sosial dan ekonomi (Tang et al., 2015; Radiarta et al., 2014; Alexander et al., 2016).

\section{SIMPULAN DAN SARAN}

Program pengabdiaan KKN-PPM dapat meningkatkan pengetahuan dan keterampilan kelompok sasaran dalam memanfaatkan potensi sumberdaya secara optimal dalam rangka pengembangan pulau wisata Camba-cambang. Diharapkan kepada para pemangku kepentingan untuk tetap melanjutkan program kerja yang telah dilaksanakan.

\section{UCAPAN TERIMA KASIH}

Terima kasih kepada : (1) Direktorat Riset dan Pengabdian Masyarakat (DRPM), Ditjen Penguatan Riset dan Pengembangan Kemenristekdikti atas dana pengabdian tahun anggaran 2019 Nomor Kontrak 1571/L.9/AK/2019, (2) Yayasan Pendidikan Balik Diwa dan STITEK Balik Diwa Makassar atas dana pendukung dan fasilitasnya, (3) Dinas Kelautan dan Perikanan Provinsi Sulawesi Selatan atas rekomendasi kegiatannya, (4) Pemerintah Kabupaten Pangkajene dan Kepulauan, Pemerintah Kecamatan Liukang Tupabbiring Utara, Pemerintah dan Masyarakat Desa Mattiro Baji atas izin dan kerjasamanya, serta (5) para mahasiswa peserta KKN-PPM STITEK Balik Diwa Tahun 2019.

\section{DAFTAR RUJUKAN}

Alexander, K. A., Angel, D., Freeman, S., Israel, D., Johansen, J., Kletou, D., ... Potts, T. (2016). Improving sustainability of aquaculture in Europe: Stakeholder dialogues on integrated multi-trophic aquaculture (IMTA). Environmental Science \& Policy, 55, 96-106.

Bambang N, Widodo, Suryadi A, Wassahua Z. 2011. Apartemen ikan (fish apartment) sebagai pilar pelestarian sumberdaya ikan. Jakarta: Balai Besar Pengembangan Penangkapan Ikan, Direktorat Jendral Perikanan Tangkap, Kementrian Kelautan dan Perikanan.

Besra, E., 2012. Potensi wisata kuliner dalam mendukung pariwisata di Kota Padang. Jurnal Riset Akuntansi dan Bisnis. 12(1) : 74-101. 


\section{KKN PPM Masyarakat Lingkar Pulai (Hariansyah, Fatahuddin, Tamti, Safitri, Lawi,}

Kabangnga, Ikramullah) | 74

Buck, B.H., M.F. Troell, G. Krause, D.L. Angel, B. Grote, \& T. Chopin, 2018. State of the art and challenges for offshore IMTA. Front. Mar. Sci. 5:165.

Budhiman, A. A. 2011. Panduan pelaksanaan pengembangan rumah ikan. Semarang: Balai Besar Pengembangan Penangkapan Ikan, Direktorat Jendral Perikanan Tangkap.

Chopin, T., J.A. Cooper, G. Reid, S. Cross, \& C. Moore, 2012. Open-water integrated multi-trophic aquaculture:. Reviews in Aquaculture. 4: 209-220.

Eriksen M, Lebreton LCM, Carson HS, Thiel M, Moore CJ, Borerro JC, Ryan PG. 2014. Plastic Pollution in the World ' s Oceans : 1-15. https://doi.org/10.1371/journal.pone.0111913

Farrell, P. \& Nelson, K., 2013. Trophic Level Transfer of Microplastic: Mytilus edulis (L.) to Carcinus maenas (L.). Environ. Pollut. 177 :1-3.

Fleming, L.E., N. McDonough, M. Austen, L. Mee, M.Moore, P. Hess, M.H. Depledge, M.White, K. Philippart, P. Bradbrook \& .Smalley, A.,2014. Oceans and HumanHealth: A Rising Tide of Challenges andOpportunities for Europe. Mar. Environ. Res. 99:16-19.

Harrison, J.P., M. Sapp, M. Schratzberger \& Osborn, A.M., 2011. Interactions between Microorganisms \& Marine Microplastics: a call for research. Mar. Tech. Socie. J. 45:12-20.

Haward M.. 2018. Plastic pollution of the world 's seas and oceans as a contemporary challenge in ocean governance. Nature Commun. 9 (1): 667. doi.org/10.1038/s41467-018-03104-3.

Heriansah dan Fathuddin. 2014. Upaya pengembangan usaha alternatif masyarakat dalam pemanfaatan potensi pulau di Kabupaten Pangkep. Jurnal Balik Diwa. 5(1): 36-44. http://www.stitek-balikdiwa.ac.id/images/jbd v5n1 6

Karim, M, A. Susilowati, dan J. Saokani. 2013. Identifikasi hasil diversifikasi dan pengembangan aneka produk olahan ikan teri khas Makassar. Jurnal Balik Diwa. 4(2): 19-28. http://www.stitek-balikdiwa.ac.id/images/jbd v4n2 4

Kristiana Y., M. T Suryadi, S. R. Sunarya, 2018. Eksplorasi Potensi Wisata Kuliner untuk Pengembangan Pariwisata di Kota Tangerang. Jurnal Khasanah Ilmu. 9(1): 18-23.

Jambeck, J.R., R. Geyer, C. Wilcox, T.R. Siegler, M.Perryman, A. Andrady, R. Narayan, \&Law, K.L., 2015. Plastic waste inputs fromland into the ocean. Science. 347:768-771.

Jena, A. K., P. Biswas, \& H. Saha, 2017. Advanced farming systems in aquaculture: strategies to enhance the production. Innovative Farming, 2(1): 84-89.

Mujiburrahmad dan Firmansyah, 2014. Hubungan faktor individu dan lingkungan sosial dengan partisipasi masyarakat dalam pengelolaan sampah rumah tangga. Agrisep. 1(15): 47-66.

NOAA [National Oceanic and Atmospheric Administration]. 2013. Programmatic Environmental Assessment (PEA) for the NOAA Marine Debris Program (MDP). Maryland (US): NOAA.

Radiarta, I. N., Erlania, \& Sugama, K. 2014. Budidaya rumput laut, Kappaphycus alvarezii secara terintegrasi dengan ikan kerapu di Teluk Gerupuk Kabupaten Lombok Tengah, Nusa Tenggara Barat. Riset Akuakultur, 9(1), 125-134.

Rahadi, Regina Kristiawati, Nazarudin. 2001. Agribisnis perikanan. Cetakan XI. Bogor: PT Swadaya.

Rendle, E.J., dan Rodwell, L.D. (2014). Artificial surf reefs: A preliminary assessment of the potential to enhance a coastal economy. Marine Policy. 45: 349-358. doi.org/ 10.1016/j.marpol.2013.09.004.

Sutrisnawati, K dan R. M.Purwahita, 2018. Fenomena sampah dan pariwisata Bali. Jurnal Ilmiah Hospitality Management. 9(1): 49-56.

Tang, J., Dai, Y., Wang, Y., Qin, J. G., \& Li, Y. (2015). Improvement of fi sh and pearl yields and nutrient utilization efficiency through fish - mussel integration and feed supplementation. Aquaculture, 448, 321-326. doi.org/10.1016/j.aquaculture.2015.05.028.

Tjiptono, F. 1999. Strategi pemasaran. Yogyakarta: Andi Offset.

Uneputty, P. A., \& Evans, S. M., 1997. Accumulation of beach litter on islands of the Pulau Seribu Archipelago, Indonesia. Marine Pollution Bulletin. 34(8): 652-655.

Willoughby, N. G., Sangkoyo, H., \& Lakaseru, B. O., 1997. Beach litter: an increasing and changing problem for Indonesia. Marine Pollution Bulletin. 34(6): 469-478

Zhang, J., D. Kitazawa, \& C. Yang, 2015. A numerical modeling approach to support decisionmaking on design of IMTA for efficiently mitigating aquatic waste. Mitig. Adapt. Strateg. Glob. Change. 